\title{
Kenneth E. Wilkening, Acid Rain Science and Politics in Japan
}

(Cambridge, MA: The MIT Press, 2004)

\author{
Paul Erickson
}

Received: 22 November 2007 / Accepted: 22 November 2007 /

Published online: 17 April 2008

(C) National Science Council, Taiwan 2008

Much recent scholarship in science and technology studies has focused on understanding the local dimensions of transnational environmental problems. How do environmental issues - which typically draw their strength from intensely local issues of resource use, subsistence livelihoods, and social conflict-become the subject of global knowledge-making and politicking? How does the knowledge produced by international scientific communities and the consensus forged by global political agreements acquire legitimacy and force in local environmental and cultural contexts? Answering these difficult questions is a critical first step in creating a more sustainable future for the planet. Kenneth Wilkening contributes to our understanding of these questions in his fascinating account of the history and current status of acid rain research and policy in Japan. The story he relates explains much about why Japan has become a leader in the creation of East Asian environmental accords in recent decades, and what this phenomenon has meant for the way environmental problems in the region are approached.

Wilkening structures his inquiry by addressing three central questions. First, "how and why has Japan gone about acquiring scientific knowledge related to aciddeposition phenomena?" Second, "How, and under what circumstances, have scientists and scientific knowledge influenced public policymaking in Japan on the acid deposition issue?" And finally, "If influential, did this steer Japan toward acid deposition sustainability, why or why not?" (13). To articulate answers to these questions, he draws loosely upon several concepts in science and technology studies. Modern Japan, he suggests, has undergone a number of changes in its "problem framework" (which includes features of Kuhn's "paradigms," Foucault's "epistemes," Lakatos's "research programs," and Joan Fujimura's "standard package") for addressing acid deposition. However, problem frameworks extend beyond science proper, including facets of political and popular culture. It is therefore imperative to identify "bridging objects," a "fact, concept, method, procedure, research institution, etc." that creates

P. Erickson $(\bowtie)$

Science, Technology, \& Public Policy Program, University of Michigan, Ann Arbor, MI, USA

e-mail: perckson@umich.edu 
shared understandings between different social worlds. Bridging objects are essential for creating productive working relationships between Japanese scientists and western scientists, between scientists and bureaucratic policymakers, and between scientists and the Japanese public.

Using these concepts, Wilkening discusses six periods in the history of the "acid deposition problem" in Japan, each characterized by a unique (if sometimes vaguely defined) problem framework, and by the presence (or more often absence) of bridging objects between science and policy. The histories of many of these periods are new to the English-language literature; moreover, by extending the narrative from the time of the Meiji restoration down to the present day, Wilkening is able to grasp several overarching trends and patterns that might otherwise be missed. For example, early controversies surrounding acid deposition were bound up with issues of acute and localized industrial pollution, thereby restricting the policy focus to the mitigation of health effects and agricultural impacts of acids. Only in the 1980s did the framing of the acid deposition problem become more "ecological"-looking more broadly at the environmental impacts of deposition upon Japanese soils and forests - due in part to the growing influence of Western environmental science and politics. Similarly, prior to the 1980s, the science of acid deposition developed significantly (in part under Western influences), but remained substantially removed from political decision-making about pollution and development. Subsequently, the acid deposition scientists have become significant in shaping research policy and programs that transfer clean technologies to reduce regional acidifying emissions, but have played less of a role in developing Japanese regulatory policy. This shift, Wilkening argues, was the result of a new, uniquely Japanese problem framework that successfully bridged the worlds of the scientists and the all-powerful bureaucrats. Yet ultimately, Japan's journey toward sustainability remains unfinished, and it seems likely that further shifts in problem framing may be required before this elusive destination is reached.

Some of Wilkening's most compelling writing comes in more recent portions of his history, for example, when he outlines the ways in which Japanese bureaucracies create and use information and structure channels of government accountability to the needs of citizens. While "direct channels for citizen input into policymaking are essentially nonexistent" in Japan (201), bureaucrats nevertheless engage in intense competition for government funding and influence under the gaze of an attentive public and press. In these sections too we glimpse the cultural underpinnings of Japan's environmental consciousness, most notably the national "culture of forests" that effectively localized concern over acid degradation in the 1980s. In a fascinating comparison, Wilkening narrates the origins of acid rain science and politics in Europe as part of a Scandanavian "culture of lakes," something utterly foreign to Japan's geography of forested mountains and narrow coastal plains. It was only when research raised the possibility that acid deposition could cause widespread forest degradation that Japan's "ecological" conception of the problem began to take hold.

Yet while Wilkening intends his notions of "problem frameworks" and "bridging objects" to encompass more than purely scientific features of the acid deposition problem, the narrative in much of this book remains unapologetically close to his analysis of scholarly scientific research programs. As a result, especially in earlier 
chapters of the book, his exploration of political and cultural context is relatively less deep. Yet even here Wilkening drops provocative hints that suggest potentially deep insights into the dynamics of environmental science, politics, and culture in Japan. For instance, given that the early Japanese scientific community was dominated by pre-existing cultural elites (e.g., members of samurai families), what kind of impact might this have had on the framing of acid deposition problems? In what ways might these scientists' social status enable or constrain their research programs and their avenues for political action on environmental issues? The effect is to leave the reader hoping for more insight into the motivations of the actors involved and greater richness of plot.

But of course, the fact that such questions continue to tantalize should not be construed as a criticism. Wilkening's book represents an invaluable contribution to our understanding of the science and politics of acid rain, to the comparative study of environmental governance, and to our knowledge of the evolution of environmental science. 